American Journal of Pharmaceutical Education 2019; 83 (4) Article 6651.

\title{
RESEARCH
}

\section{A Multimodal Approach to Teaching Cultural Competency in the Doctor of Pharmacy Curriculum}

\author{
Gina M. Prescott, PharmD, Alyssa Nobel, PharmD \\ University at Buffalo School of Pharmacy and Pharmaceutical Sciences, Buffalo, New York \\ Submitted July 13, 2017; accepted November 20, 2017; published May 2019.
}

\begin{abstract}
Objective. To assess first-year pharmacy students' grades and preferred teaching styles within a multimodal teaching approach for developing cultural competency during a required Pharmaceutical Care I course.

Methods. A lecture, two active-learning exercises (global bead and trading places), and an in-class quiz were used to teach students about cultural competency in preparation for a practicum. A four-hour practicum consisting of videos, structured discussion, counseling, and a survey were used in this multimodal approach. Student quiz and practicum grades and survey results were analyzed. Reflection responses were collected.

Results. Students scored an average of $86.1 \%$ on the in-class quiz and $92.6 \%$ on the practicum. Average rankings on the Trading Places exercise demonstrated a change in students' individual biases. Students perceived the practicum, lecture, and Worlds Apart videos to be the most useful elements of the cultural competency curriculum.

Conclusion. The practicum and lecture were the teaching methods most preferred by students for conveying cultural competency; however, students agreed that all of the teaching methods used helped them to achieve the desired learning objectives. Students' grades improved from the quiz to the practicum, which may indicate enhanced cultural knowledge via a multimodal teaching approach.
\end{abstract}

Keywords: cultural competency, pharmacy education, teaching, active learning, diversity

\section{INTRODUCTION}

Cultural competency is essential for pharmacists and other health care providers to effectively communicate with and provide advanced care for individual patients. When providing patient care, health care providers need to consider not only the patients' physical needs, but also their spiritual, psychological, and cultural needs. Cultural competency can be defined as the attitudes, knowledge, skills, and values that an individual develops over time and uses to work effectively in a cross-cultural environment. ${ }^{1}$ Cultural humility is another term that is often used and sometimes preferred over cultural competency as it emphasizes the need for lifelong self-evaluation and critique without the achievement of mastery or competency. ${ }^{2}$ The Accreditation Council for Pharmacy Education (ACPE) Standards includes the need for "students' demonstration of cultural awareness and sensitivity." 3 This skill will be increasingly important as the population of the United States continues to become more

Corresponding Author: Gina M. Prescott, University at Buffalo School of Pharmacy and Pharmaceutical Sciences, 215 Kapoor Hall, Buffalo, NY 14214-8033. Tel: 716-6454784. Fax: 716-829-6093. E-mail: gmzurick@buffalo.edu diverse. Researchers estimate that by 2044 the United States will no longer have a race or ethnic group that makes up the majority of the population. ${ }^{4}$ Teaching cultural awareness to students at the University at Buffalo as they enter communities to provide patient care is extremely important because the city serves a large foreign-born population. There are over 10,000 refugees who have resettled here since 2001, and the University at Buffalo has over 4500 international students from over 100 different countries. ${ }^{5,6}$ Teaching students cultural competency is a requirement of the pharmacy curriculum, but ideal standards and guidelines do not exist. ${ }^{3}$ Multiple studies investigating different teaching methods have been conducted at schools of pharmacy as well as at nursing and medical schools. ${ }^{7-13}$

Medical schools have successfully used reflective learning, patient clinic encounters, lectures, visual media, readings, demonstrations and simulations, and in-class cases to train their students in cultural competency. ${ }^{9,11}$ These various methods aim to foster effective communication, self-directed independent learning, critical thinking, and problem solving. ${ }^{9}$ Nursing schools have an outlined "blueprint" available to help integrate cultural 


\section{American Journal of Pharmaceutical Education 2019; 83 (4) Article 6651.}

competency into their curriculums. ${ }^{10}$ This framework is complete with examples, learning objectives, and key terms to know.

Various teaching strategies have been used to educate Doctor of Pharmacy (PharmD) students about cultural competency. Poirier and colleagues used a variety of team-based learning techniques (readiness assessment tests, reflections, panel discussions and group presentations), to develop cultural competency, enhance selfawareness, address cultural knowledge, and develop health strategy skills. Competency was measured and increased by using the Inventory for Assessing the Process of Cultural Competence Among Healthcare Professionals (IAPCC-R) survey. ${ }^{12}$ Several approaches were used at another school during a two-semester sequence that included books, videos, simulations, group activities, and case discussions to improve students' abilities to provide culturally competent care. Analysis of reflective papers and student surveys demonstrated increased understanding. ${ }^{13}$ A study by Arif and colleagues used simulated vignettes with small-group discussion to improve students' understanding and attitudes towards cross cultural communication. ${ }^{8}$ Improvement in this area was demonstrated by pre- and posttest surveys. Additionally, in a one-hour practicum, students were divided into three different learning-style groups (a simulated-patient exercise, traditional lecture, and case-based learning) to determine which would enhance the students' cultural competency and to what degree. ${ }^{7}$ Each group improved in certain cultural competency domain scores, but no approach on its own was sufficient. This suggests that a combination of several strategies may be necessary to impact students' comprehension of cultural competency.

While several different teaching methods in the cultural competency setting have been studied, no single approach has been deemed superior to others and no studies exist that use multiple active and passive approaches for comparison. Our study aimed to incorporate and assess a multimodal approach to teaching cultural competency to a first-professional year pharmacy (P1) class during a lecture and practicum within a Pharmaceutical Care I course.

\section{METHODS}

First-year professional pharmacy (P1) students $(n=136)$ at the University at Buffalo School of Pharmacy enrolled in the required Pharmaceutical Care I course during fall 2016 were included in this analysis. The majority of the students in the class were female (57\%) and selfidentified as white (49\%) or Asian (38\%). The average age was 21 years. Almost all students were New York residents $(93 \%)$ and only a few were non-US citizens (3\%).
A 110-minute lecture session followed by a fourhour practicum was allotted for teaching cultural knowledge and competency within the Pharmaceutical Care I course. Various teaching components (Table 1) were used and then students were given 20 minutes at the end of class to complete a nine-item multiple-choice quiz designed to assess the learning objectives of the lecture.

For the practicum, the class was divided into four groups and third-year professional pharmacy (P3) teaching assistants (TAs) facilitated the videos, structured discussion, and counseling sessions. For the counseling sessions, students were allocated 10 minutes to counsel their patient on a new prescription while navigating the cultural intricacies of the case, identifying a cultural barrier to health, encouraging safe cultural practices, and determining a solution that fit the patient's needs. Four separate and unique patient cases were developed specifically for this practicum (Table 2). Each student was randomly assigned to only one case. One TA role-played the patient, while another TA observed and graded the interaction based on a defined rubric. Following the interaction, students answered seven reflection questions intended to help them identify similarities and differences between themselves and their patient and determine what personal improvements they could make for the future. Additionally, students also completed an 11-question survey instrument designed to assess students' preferred teaching methods. All data was deidentified after grades were submitted to the university after the fall 2016 semester. Data analysis of the academic grades and survey instruments were completed using descriptive statistics. Reflective questions were reviewed by the lead TA and course instructor for the following themes: critical thinking, alternative medications, counseling techniques, and general cultural awareness. The University at Buffalo Investigational Review Board deemed this study exempt.

\section{RESULTS}

Students scored a mean grade of $86.1 \%$ (median $=88.9 \%)$ on the in-class quiz. They scored $\geq 85 \%$ on questions regarding: the national standards for Culturally and Linguistically Appropriate Services (CLAS) with respect to health care, general family cultural differences, and some key terms (refugee, immigrant, integration, assimilation). The mean student scores on terminologies such as the difference between acculturation and cultural skills were lower $(75 \%$, respectively).

During the Trading Places exercise, most students' opinions changed as individual profiles expanded in depth (Figure 1). Profiles that were most desirable in round 1 fell to least desirable by round 3 after different characteristics 
American Journal of Pharmaceutical Education 2019; 83 (4) Article 6651.

Table 1. Description of Teaching Modalities Used During the Lecture and Practicum

\begin{tabular}{|c|c|c|c|}
\hline Teaching Method & Description & Rationale & $\begin{array}{l}\text { Time Period } \\
\text { Allocated }\end{array}$ \\
\hline $\begin{array}{l}\text { Global Beads } \\
\text { Activity }^{18}\end{array}$ & $\begin{array}{l}\text { Students were given different colored } \\
\text { beads, each representing a different } \\
\text { ethnicity. They were asked questions } \\
\text { regarding the ethnicity of friends, } \\
\text { family, and neighbors at different } \\
\text { stages of their lives and answered } \\
\text { accordingly using the beads to } \\
\text { create a visual representation of the } \\
\text { cultures they have most closely } \\
\text { interacted with throughout their lives. }\end{array}$ & $\begin{array}{l}\text { To identify one's own background/ } \\
\text { cultural awareness }\end{array}$ & $\begin{array}{l}\text { First class activity, } \\
15 \text { minutes }\end{array}$ \\
\hline Didactic Lecture & PowerPoint presentation. & $\begin{array}{l}\text { To introduce key terms/definitions, } \\
\text { review the impact culture can } \\
\text { have on patient health, and } \\
\text { introduce medical considerations } \\
\text { on specific ethnicities and } \\
\text { religions }\end{array}$ & $\begin{array}{l}\text { Second class } \\
\text { activity, } \\
60 \text { minutes }\end{array}$ \\
\hline $\begin{array}{l}\text { Trading Places } \\
\text { Exercise }^{19}\end{array}$ & $\begin{array}{l}\text { Students were presented with the profiles } \\
\text { of four people and were asked to pick } \\
\text { which person they would rather be, } \\
\text { ranking their choices from } 1 \text { (most } \\
\text { desirable) to } 4 \text { (least desirable). They } \\
\text { answered this question twice more } \\
\text { after additional details were added to } \\
\text { the profiles each time. The exercise } \\
\text { completed on SurveyMonkey that } \\
\text { eliminated the ability to reverse to } \\
\text { previous questions to change an } \\
\text { answer. }\end{array}$ & To understand own bias/ stereotypes & $\begin{array}{l}\text { Third class } \\
\text { activity, } \\
15 \text { minutes }\end{array}$ \\
\hline Structured Discussion & $\begin{array}{l}\text { Key themes of the videos were discussed } \\
\text { with TAs }\end{array}$ & $\begin{array}{l}\text { Provide students with challenges and } \\
\text { considerations for providing } \\
\text { cultural care }\end{array}$ & $\begin{array}{l}\text { Second practicum } \\
\text { activity, } 10 \\
\text { minutes }\end{array}$ \\
\hline $\begin{array}{l}\text { Counseling } \\
\text { Sessions/Reflection }\end{array}$ & Patient-pharmacist interaction & $\begin{array}{l}\text { Application of the cultural } \\
\text { approaches above }\end{array}$ & $\begin{array}{l}\text { Third practicum } \\
\text { activity, } 20 \\
\text { minutes }\end{array}$ \\
\hline
\end{tabular}

about each patient, such as health, family, and monetary status, were revealed. Post-completion comments about their ranking rationales included: initial appeal of the lifestyles, differing views on family (children vs no children), situations students would rather avoid, money, happiness, a successful career, health, and ease of life. Generally speaking, the comments reflected the students' values.

The mean counseling score was $92.6 \%$ (median $=94.7 \%$ ). Students' reflective responses post-practicum were also analyzed and graded only for completeness and factored in as part of the total practicum grade. Student self-reflection on the counseling session identified the following themes: "gain the patient's trust first and build a relationship," "listen," "ask more questions" (specifically open-ended questions), "put the patient's needs and concerns first," "think critically," "incorporate complementary alternative medicine into treatment as long as it is safe," "give the patient several options and let them pick which choice is best for them," and "think about the patient, rather than the rubric."

The post-practicum survey questions and response rates can be found in Table 3. The Trading Places 
American Journal of Pharmaceutical Education 2019; 83 (4) Article 6651.

Table 2. Practicum Patient Case Descriptions

\begin{tabular}{|c|c|c|c|}
\hline $\begin{array}{l}\text { Case } \\
\text { Number }\end{array}$ & $\begin{array}{c}\text { Patient } \\
\text { Demographics }\end{array}$ & Prescription & Description \\
\hline 1 & $\begin{array}{l}\text { Asian female, } \\
\text { age } 34\end{array}$ & $\begin{array}{l}\text { Prednisone, } 5 \mathrm{mg} \\
\text { QAM }\end{array}$ & $\begin{array}{l}\text { Patient uses herbal supplements including salvia for her joint injuries, rhubarb for } \\
\text { inflammation and pain, and ginseng for her spirit. She is unsure of what her } \\
\text { new medication is for and typically only takes her natural medications when } \\
\text { she needs them. She is upset to hear there are side effects from the medication. } \\
\text { She worries about whether her elders will approve of this and thought her } \\
\text { doctor would prescribe a natural product. }\end{array}$ \\
\hline 2 & $\begin{array}{l}\text { Muslim male, } \\
\text { age } 70\end{array}$ & $\begin{array}{l}\text { Metoprolol Tartrate, } \\
50 \mathrm{mg} \text { BID }\end{array}$ & $\begin{array}{l}\text { Patient is preparing for a pilgrimage to Mecca. He has been prescribed several } \\
\text { other medications for his heart and has them at home but is unsure if he wants } \\
\text { to take them or not. He values the opinion of his family and wants to speak } \\
\text { with them first. He knows his medical condition is declining and he may die } \\
\text { soon, so he is prioritizing the pilgrimage to Mecca. He is overwhelmed with } \\
\text { managing his health. }\end{array}$ \\
\hline 4 & $\begin{array}{c}\text { Refugee } \\
\text { female, } \\
\text { age } 35\end{array}$ & $\begin{array}{l}\text { Omeprazole, } 20 \mathrm{mg} \\
\text { QD }\end{array}$ & $\begin{array}{l}\text { Patient is a Syrian refugee and mother of } 3 \text { children who have all recently moved } \\
\text { to the US. Her acid reflux developed upon arrival. She used to cook all the } \\
\text { foods in her homeland (meat, vegetables, some spices), but now they eat fast } \\
\text { food because it is cheap, geographically close, and she doesn't have a car that } \\
\text { can easily get her to the grocery store. She doesn't like the food here and } \\
\text { misses preparing foods for her family. }\end{array}$ \\
\hline
\end{tabular}

exercise, designed to raise bias awareness, was scored the lowest. Students' survey responses showed that although they did not have many culturally diverse relationships, they did agree on the importance of being culturally aware and having the ability to effectively communicate with patients.

\section{DISCUSSION}

Teaching cultural competency via a multimodal approach was well received by the P1 students. Using a multimodal approach to teaching cultural competency allows for the use of different methods to assist in highlighting foundational principles and enables teachers to reach and engage a variety of learners. Students scored well on the in-class quiz (86.1\%) but performed better on the practicum (92.6\%). This improvement may indicate enhanced cultural knowledge and awareness that resulted from a multimodal teaching approach and emphasizes the utility of using active-learning for teaching cultural competency. ${ }^{13}$ Incorporation of active learning also provides
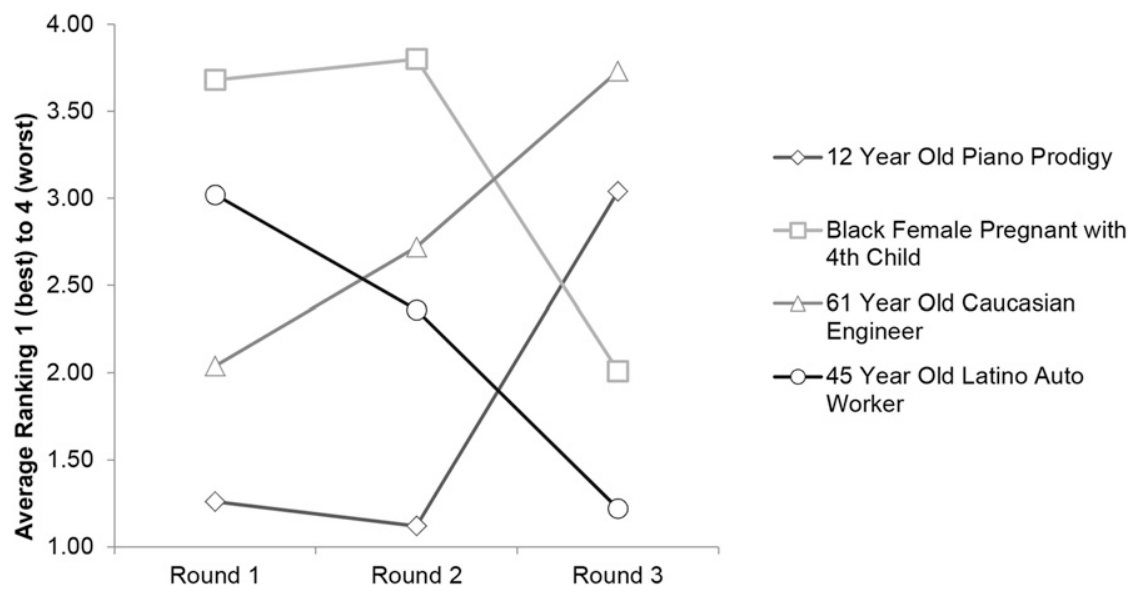

Figure 1. Trading Places Rankings by Round 
American Journal of Pharmaceutical Education 2019; 83 (4) Article 6651.

Table 3. Students' Perceptions of Learning and Teaching Methods ${ }^{\mathrm{a}}$

\begin{tabular}{|c|c|c|c|c|c|c|c|}
\hline Question & $\begin{array}{c}\text { Strongly } \\
\text { Disagree } \\
\text { n }(\%)\end{array}$ & $\begin{array}{l}\text { Disagree } \\
\text { n }(\%)\end{array}$ & $\begin{array}{c}\text { Neither } \\
\text { agree nor } \\
\text { disagree } \\
\text { n (\%) }\end{array}$ & $\begin{array}{l}\text { Agree } \\
\text { n }(\%)\end{array}$ & $\begin{array}{l}\text { Strongly } \\
\text { Agree } \\
\text { n (\%) }\end{array}$ & Mean & Mode \\
\hline $\begin{array}{l}\text { The Global Beads activity helped me better } \\
\text { understand my own background. }\end{array}$ & $3(2.2)$ & $9(6.6)$ & $29(21.3)$ & $67(49.3)$ & $28(20.6)$ & 3.8 & 4 \\
\hline $\begin{array}{l}\text { The lecture helped me understand different cultural } \\
\text { terms, like acculturation, refugee, and immigrant. }\end{array}$ & $1(0.7)$ & $5(3.7)$ & $11(8.1)$ & $74(54.4)$ & $45(33.1)$ & 4.2 & 4 \\
\hline $\begin{array}{l}\text { The Trading Places activity made me more aware of } \\
\text { my own bias. }\end{array}$ & $3(2.2)$ & $5(3.7)$ & $39(28.7)$ & $68(50)$ & $21(15.4)$ & 3.7 & 4 \\
\hline $\begin{array}{l}\text { The Worlds Apart videos provided good visual } \\
\text { examples of culturally diverse patient/provider } \\
\text { encounters. }\end{array}$ & $1(0.7)$ & $3(2.2)$ & $20(14.7)$ & $75(55.1)$ & $37(27.2)$ & 4.1 & 4 \\
\hline $\begin{array}{l}\text { A practicum in which the patient is culturally diverse } \\
\text { enabled me to work through unique problems. }\end{array}$ & $1(0.7)$ & $3(2.2)$ & $10(7.4)$ & $67(49.3)$ & $55(40.4)$ & 4.3 & 4 \\
\hline $\begin{array}{l}\text { I have had culturally diverse relationships throughout } \\
\text { my life. }\end{array}$ & $6(4.4)$ & $21(15.4)$ & $13(9.6)$ & $59(43.4)$ & $37(27.2)$ & 3.6 & 4 \\
\hline I am culturally aware of the people around me. & $0(0)$ & $2(1.5)$ & $13(9.6)$ & $86(63.2)$ & $35(25.7)$ & 4.1 & 4 \\
\hline $\begin{array}{l}\text { I can effectively communicate with culturally diverse } \\
\text { patients. }\end{array}$ & $0(0)$ & $6(4.4)$ & $23(16.9)$ & $81(59.6)$ & $26(19.1)$ & 4.0 & 4 \\
\hline $\begin{array}{l}\text { In order to effectively care for patients, it is necessary } \\
\text { to know a patient's beliefs and cultural background. }\end{array}$ & $0(0)$ & $0(0)$ & $2(1.5)$ & $36(26.5)$ & $98(72.1)$ & 4.7 & 5 \\
\hline Cultural competency is something I have mastered. & $9(6.6)$ & $24(17.6)$ & $49(36)$ & $46(33.8)$ & $8(5.9)$ & 3.2 & 3 \\
\hline $\begin{array}{l}\text { A patient's personal goals are more important than the } \\
\text { pharmacist/ practitioner's goals. }\end{array}$ & $0(0)$ & $4(2.9)$ & $41(30.1)$ & $56(41.2)$ & $35(25.7)$ & 3.9 & 4 \\
\hline
\end{tabular}

${ }^{a}$ Rated on a Likert scale on which $1=$ strongly disagree, $2=$ disagree, $3=$ neither agree nor disagree, $4=$ agree, $5=$ strongly agree

an opportunity for students to apply cultural principles learned in class and during the structured discussion. These results were similar to those of previous studies that used a variety of teaching methods and demonstrated an increase in certain aspects of cultural competency. However, our study differed in that it did not use a standardized cultural assessment survey tool.

Our students agreed or strongly agreed that three of the five methods helped them in their cultural awareness when caring for patients. These activities (the practicum, lecture, and videos) had more obvious practical implications for learning how to care for a culturally diverse patient. Students scored the lecture highly, and this was surprising because often students are not challenged or captivated by standard lectures. ${ }^{13}$ In this case, their interest may have been improved by dividing the 110-minute presentation up on both ends by activities, leaving just 60 minutes of actual lecturing. Interestingly, the two activities designed for student self-refection (Global Beads and Trading Places) were the least preferred activities. Students may have been less interested in self-reflection or had not had tremendous experience in this area. They may have also been unaware of the significance that cultural differences play in a patient-pharmacist interaction or had the expectation that they were here to care for patients, so the accumulated knowledge was more important. This is an important point to consider because a vital initial step in embarking on the journey towards cultural competency is to acknowledge the influence of one's own background and bias. Previous studies have shown initial apprehension, struggle, and confusion from students regarding reflective assignments, but that ultimately the students perceive the method as a valuable tool for self-improvement. ${ }^{14}$ Student preference of the learning activities used was not assessed in previous studies.

The students did not come from culturally diverse backgrounds, but did consider themselves culturally aware. Where this knowledge was acquired or the depth of this awareness is unknown. However, millennials are growing up in a diverse world where the acceptance of previously controversial topics such as sexuality and race is now the norm. ${ }^{15}$ Students also agreed or strongly agreed that it is important to know about a patient's culture in order to care for them better. However, a discrepancy with this is the lower agreement in regards to patient personal goals. This could be because of the emphasis in the medical field on providing evidence-based medical care that does not usually address factors such as the patient's culture or personal preferences. ${ }^{16}$ 


\section{American Journal of Pharmaceutical Education 2019; 83 (4) Article 6651.}

Finally, similar to all the other previous studies, students still felt that they were not fully prepared to effectively communicate with a culturally diverse patient or have mastered cultural competency. This is not an unexpected finding because cultural competency is not an endpoint but rather a skill that is continually improved over time. ${ }^{7}$ In order to effectively communicate with a diverse population, pharmacy students need trust, repeat opportunities to interact (didactic, simulation, experiential), and time. This demonstrates that ongoing cultural experiences should be integrated throughout the curriculum and beyond, and that a single class period is not sufficient to achieve the desired results.

Limitations to our study included the design of the quiz which focused predominately on facts and possible grading variability with different teaching assistants. These could have contributed to these differences in the improved grades in the practicum compared to lecture. Also, the survey was not designed to address students' previous cultural experiences or awareness, and this may have altered the students' self-reflection. Some additional limitations to our study include the demographics of our class, which is comparable to the AACP data regarding students who earned degrees following the $2015-2016$ academic year ( $49 \%$ vs $53.2 \%$ Caucasian, $38 \%$ vs $24.6 \%$ Asian American, and $57 \%$ vs $61.3 \%$ female, respectively). ${ }^{17}$ Although the demographics of our class were similar to the national averages for sex and ethnicity of pharmacy students, these values may not be representative of every individual school of pharmacy. Additionally, this study only focused on cultural competency in the settings of ethnicity, gender, and religion. In the future, it would be advantageous to expand upon these factors to include sexuality, socioeconomic status, and disabilities. Another limitation of this study may have been the use of TAs acting as patients for the practicum. Although TAs were specifically selected based on their gender and ethnicity to match the patient cases as closely as possible, live patients or actors may have been more beneficial and realistic. The final limitation to this study is the fact that there were no data from previous years that would allow us to compare the difference between a single-modal approach and a multimodal approach. We also have no long-term data to validate improved cultural humility over time or throughout the students' education or career.

\section{CONCLUSION}

Previous studies have shown there are several effective teaching methods, both passive and active, that can be used to teach cultural competency. With limited time in the curriculum, training in cultural knowledge and awareness often must be woven into various aspects of required courses. A good way to approach incorporating cultural competency is to optimize teaching activities to include cultural intricacies when possible. Although patient counseling and lecture-based methods were preferred by students, our study found that a multimodal approach is an effective method for teaching cultural competency.

\section{REFERENCES}

1. Sias JJ, Loya AM, Rivera J, Eacute O, Islas AA. eChapter 2. Cultural Competency. In: DiPiro JT, Talbert RL, Yee GC, Matzke GR, Wells BG, Posey LM, eds. Pharmacotherapy: A

Pathophysiologic Approach, 9e. New York, NY: The McGraw-Hill Companies; 2014.

2. Tervalon M, Murray-Garcia J. Cultural humility versus cultural competence: a critical distinction in defining physician training outcomes in multicultural education. J Health Care Poor Underserved. 1998;9(2):117-125. https://doi.org/10.1353/ hpu.2010.0233. Accessed November 2017.

3. Accreditation Council for Pharmacy Education. Accreditation standards and key elements for the professional program in pharmacy leading to the doctor of pharmacy degree (standards 2016). https:// www.acpe-accredit.org/pharmd-program-accreditation/. Accessed November 2017.

4. Colby SL, Ortman, Jennifer M. Projections of the Size and Composition of the U.S. Population: 2014 to 2060. U.S. Census Bureau,. https://www.census.gov/content/dam/Census/library/ publications/2015/demo/p25-1143.pdf. Accessed November 2017. 5. City of Buffalo. New Americans Study. 2016. https:// www.ci.buffalo.ny.us/files/1_2_1/Mayor/NewAmericansStudy.pdf. Accessed November 2017.

6. University at Buffalo. International Undergraduate Admissions. https://www.buffalo.edu/internationaladmissions/get-ready-to-apply/ can-i-get-in/UB\%20Class\%20Profile.html. Accessed November 2017.

7. Sales I, Jonkman L, Connor S, Hall D. A comparison of educational interventions to enhance cultural competency in pharmacy students. Am J Pharm Educ. 2013;77(4):Article 76. 8. Arif S, Cryder B, Mazan J, Quiñones-Boex A, Cyganska A. Using patient case video vignettes to improve students' understanding of cross-cultural communication. Am J PharmEduc. 2017;81(3):Article 56.

9. Crandall SJ, George G, Marion GS, Davis S. Applying theory to the design of cultural competency training for medical students: A case study. Acad Med. 2003;78(6):588-594.

10. Cuellar NG, Brennan AMW, Vito K, de Leon Siantz ML. Cultural competence in the undergraduate nursing curriculum. J Prof Nurs. 2008;24(3):143-149. doi: 10.1016/j.profnurs.2008.01.004. 11. Kumagai AK, Lypson ML. Beyond cultural competence: critical consciousness, social justice, and multicultural education. Acad Med. 2009;84(6):782-787. doi: 10.1097/ACM.0b013e3181a42398. 12. Poirier TI, Butler LM, Devraj R, Gupchup GV, Santanello C, Lynch JC. A cultural competency course for pharmacy students. Am J Pharm Educ. 2009;73(5):Article 81.

13. Westberg SM, Bumgardner MA, Lind PR. Enhancing cultural competency in a college of pharmacy curriculum. Am J Pharm Educ. 2005;69(5):Article 82. 


\section{American Journal of Pharmaceutical Education 2019; 83 (4) Article 6651.}

14. Tsingos-Lucas C, Bosnic-Anticevich S, Smith L. A retrospective study on students' and teachers' perceptions of the reflective ability clinical assessment. Am J Pharm Educ. 2016;80(6):Article 101. 15. Pew Research Center. Millennials Confident. Connected. Open to Change. https://www.pewsocialtrends.org/2010/02/24/millennialsconfident-connected-open-to-change/. Accesssed May 2019.

16. Rogers WA. Evidence-based medicine in practice: limiting or facilitating patient choice? Health Expect. 2002;5(2):95-103. doi: 10.1046/j.1369-6513.2002.00168.x.

17. American Association of Colleges of Pharmacy. Profile of Pharmacy Students Fall 2016. 2017; http://www.aacp.org/resources/ research/institutionalresearch/Documents/PPS_2016_Intro.pdf. Accessed June 3, 2017.
18. University O. Global Beads Activity. https://oakland.edu/Assets/ upload/docs/Instructor-Handbook/Global-Beads-Activity.pdf. Accessed May 2017.

19. American Association of Colleges of Pharmacy. Health Disparities and Cultural Comptency SIG. Best practices for incorporating cultural competence training into the curriculum through active learning. https://libguides.massgeneral.org/c.php? $g=650990 \& p=4710444$. Accessed November 2017.

20. Maren Grainger-Monsen JH. Worlds apart: a series on crosscultural health care. [DVD]. Brooklyn, NY: Icarus Films; 2003. 21. Monzon J. Native Americans story on mental health. [Video]. YouTube. https://www.youtube.com/watch?v=KDFOxjdgF20. Published May 23, 2014. Accessed October 2017. 